\title{
Misoprostol como Indutor do Trabalho de Parto em Gestantes com Feto Vivo a Termo
}

Autor: Marcos Tadeu Garcia

Orientadores: Prof. Dr. Eduardo de Souza e Prof. Dr. Luiz Camano

Tese apresentada à Universidade Federal de São Paulo - Escola Paulista de Medicina, para obtenção do título de Mestre em Obstetrícia, em 13 de setembro de 2000.

Neste estudo, avaliamos o misoprostol como alternativa para a indução do parto em gestantes com feto vivo a termo. Foram analisadas 51 grávidas atendidas no período de dezembro de 1996 a fevereiro de 1998, com indicação clínica e/ou obstétrica para a resolução do parto. As grávidas apresentavam idade gestacional superior a 37 semanas, feto único, apresentação cefálica, membranas ovulares integras e índice de Bishop menor ou igual a 5 . Foram utilizados $50 \mathrm{mcg}$ de misoprostol, colocado no fórnice vaginal posterior. $\mathrm{Na}$ ausência de trabalho de parto, nova dose era administrada após 12 horas, até o máximo de 6 doses. No estudo, 29 eram primigestas (56,9\%) e 31 nuliparas $(60,8 \%)$. A indução de trabalho de parto foi alcançada em todas as pacientes com apenas uma dose do medi- camento. O parto vaginal foi realizado em 42 das 51 parturientes, sendo a incidência de cesariana de $17,6 \%$. O intervalo de tempo médio entre a ministração do misoprostol e o parto foi de 10 horas e 13 minutos, excluidos os partos cesarianos. Verificou-se o aparecimento de taquissistolia em 16 pacientes (31,4\%), não sendo observada repercussão fetal. Não foram registrados efeitos adversos sobre a mãe e o feto. $\mathrm{O}$ misoprostol como indutor do trabalho de parto mostrou-se método seguro e eficiente nas gestantes com a cérvice uterina desfavorável.

Palavras-chaves: Gravidez normal. Indução do trabalho de parto. Resolução da gravidez. Misoprostol. Prostaglandinas.

\section{Estudo Comparativo entre a Punção Aspirativa por Agulha Fina e a Biópsia de Fragmento Guiadas por Ultra-som no Diagnóstico de Lesões Mamárias Suspeitas de Malignidade}

\author{
Autor: Alexandre de Almeida Barra \\ Orientador: Prof. Cesar Alencar de Lima Rezende
}

Dissertação apresentada ao Curso de Pós-graduação em Medicina na área de concentração em Ginecologia e Obstetrícia da Faculdade de Medicina da Universidade Federal de Minas Gerais, para obtenção do Título de Mestre em 17 de dezembro de 1999.

Com o objetivo de comparar a acurácia entre a punção aspirativa por agulha fina (PAAF) e a biópsia de fragmento $(\mathrm{BF})$, utilizando o exame anatomopatológico da peça cirúrgica como padrão ouro, a PAAF e BF guiadas por ultra-som foram realizadas em 134 pacientes portadoras de lesões mamárias, palpáveis ou não, suspeitas de câncer de mama. Em 16 casos a exérese cirúrgica não foi realizada, e o padrão ouro não foi estabelecido: oito pacientes foram encaminhadas diretamente para quimioterapia e oito não se submeterem à cirurgia aberta por outros motivos. Os esfregaços citológicos obtidos através da PAAF mostraram: 69 (51,1\%) casos malignos, $24(17,8 \%)$ benignos, $15(11,1 \%)$ suspeitos e 27 (20\%) insuficientes para o diagnóstico. Após exclusão dos casos suspeitos e insuficientes, os testes de validade da PAAF mostraram: sensibilidade de $92,5 \%$, especificidade e valor preditivo positivo de $100 \%$ e valor preditivo negativo de $73,7 \%$. Foram observados quatro casos de falso negativo: Carcinoma ductal invasor bem diferenciado (2), carcinoma tubular (1), carcinoma lobular invasor (2). Os esfregaços histológicos obtidos através da BF mostraram: 87 (71,9\%) casos malignos, $32(23,7 \%)$ benignos e $6(4,4 \%)$ inadequados para a análise. Após exclusão dos casos inadequados, a BF apresentou uma sensibilidade de 95,6\%, especificidade e valor preditivo positivo de $100 \%$ e valor preditivo negativo de $84,5 \%$. A BF mostrou hiperplasia com atipia em dois casos e carcinoma in situ em três esfregaços; nos exames anatomopatológicos das peças cirúrgicas foi diagnosticado carcinoma invasor em todos eles. Estes resultados confirmam os dados da literatura que consideram ambos os métodos com alta acurácia, apresentando os resultados de material insuficiente/inadequado e a incapacidade de predizer invasão como grandes limitações da PAAF. Conclui-se também que, por ser uma técnica de amostragem, o encontro de hiperplasia ductal atipica e carcinoma in situ na biópsia de fragmento devem ser seguidos de remoção completa da lesão para classificação definitiva antes da decisão terapêutica final.

Palavras-chave: Mama: câncer, diagnóstico. Mama: doença benignas. Biópsia por agulha. 